\title{
Urbanisation in Developing Economies: Building cities that work*
}

\author{
Anthony J. Venables ${ }^{1}$ \\ ${ }^{1}$ University of Oxford, CEPR and International Growth Centre
}

Received: 22 March 2018/Accepted: 6 April 2018

\begin{abstract}
This paper reviews recent work on the economics of fast growing developing country cities, with a focus on Africa. It sets out some of the broad facts about African urbanisation and summarises two recent pieces of research work. The first argues that coordination failure can create multiple equilibria and divergent paths of development, some in which cities are internationally competitive and able to create jobs, others in which cities are stuck in a 'non-tradables trap'. The second is a dynamic model of city growth, calibrated to changing patterns of land-use in Nairobi; the calibration suggests a very high cost of inefficient land use in the context of urban slums.
\end{abstract}

JEL classification: O18, O55, R0, R5

Key words: Urbanisation, development, Africa

\section{Introduction}

Urbanisation is part of the structural transformation that lies at the core of countries' economic and social development. Cities offer the promise of high productivity and job creation on a massive scale, but they can also continue to grow without delivering these benefits. They are complex environments requiring both functional market economies and extensive policy involvement. Yet our knowledge about patterns of growth and 'what works' in developing cities is quite weak. What does it take to enable a city to undertake investment - in houses, firms and factories, and in infrastructure - that keeps up with population growth and can deliver both liveability and productivity? How should public policy meet the numerous challenges that are faced? The experiences of East Asia and of Africa over recent decades illustrate how quite different paths can be followed. East Asian cities have, by and large, delivered productivity, jobs, and the housing and service provision that make cities liveable. African cities have left a large majority of their populations without either formal sector jobs or formal housing.

*Paper based on keynote address at the European Regional Science Association 2017 Conference, Groningen. Thanks to the conference organisers their invitation and audience for attention and feedback. Some of the research reported in this paper was conducted with the support of an Africa Research Program on Spatial Development of Cities at LSE and Oxford funded by the Multi Donor Trust Fund on Sustainable Urbanization of the World Bank and supported by the UK Department for International Development. I am grateful for their support. 


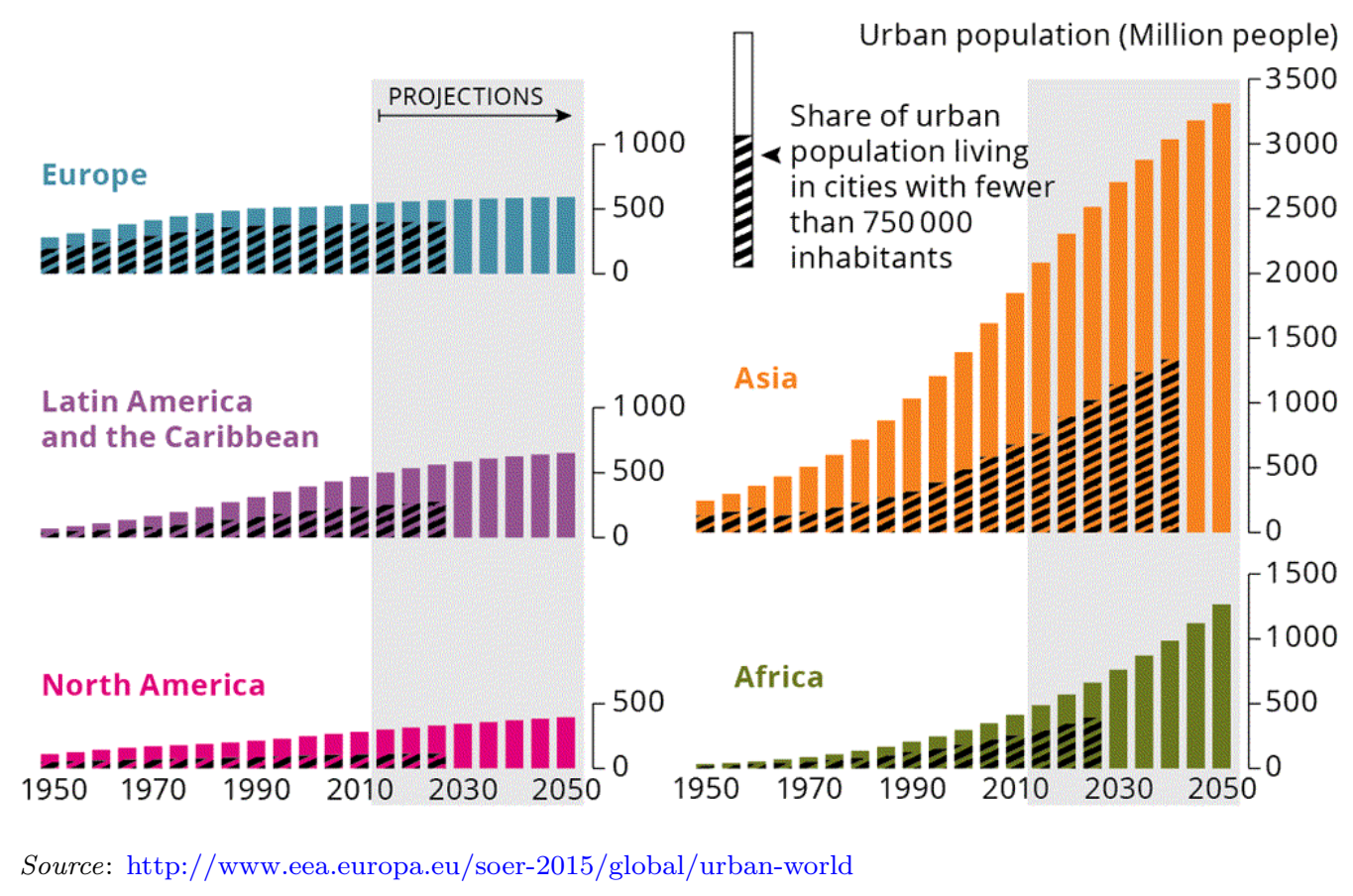

Figure 1: Urban populations

Projections indicate that in the next 40 years the urban population of the developing world will increase by 2 billion people. Most of this increase will be in Asia, but much the largest proportionate increase will be in Africa. As indicated in Figure 1, Africa's urban population is set to nearly treble by 2050 , adding 800 million people. This increment is as much as the current urban populations of Europe and North America combined. Even though urbanisation to date in Africa has been problematic, over the coming decades the continent needs to build at least twice the urban capital stock that it has built over the whole of previous history.

These observations motivate the case for better understanding urbanisation in developing economies and for using research to build the knowledge base needed to inform urban policy. A joint programme of work by researchers at the LSE, Oxford, and the World Bank has been working towards this goal for the last three years, and this paper draws on some of the work done on the project. Its focus is Africa (sub-Saharan), and principally on intra-city economics. What is going wrong, and what can be done about it? In this review we start by outlining some of the 'stylised facts' of African urbanisation and then focus on two particular pieces of work undertaken in the project. The final section of the paper draws out some of the main messages that, we think, should underpin policy choices in these cities.

\section{Some stylised facts}

Urbanisation and development. Urbanisation is an inherent part of economic development, and is an unstoppable process, regardless of what government does. Causality between urbanisation and development runs in both directions and through multiple channels. The relationship between the two is however different in Africa than in the historical experience of other regions. Urbanisation in Africa is occurring both more rapidly and at somewhat lower income levels than has been the case elsewhere. Urban population growth has been around twice as fast as was European growth at an equivalent stage of urbanisation, and around 2 percentage points higher than Asian urban population growth. There is also some indication that urbanisation is not driving the demographic transition as fast as happened elsewhere, and most of the increase in Africa's urban population is natural increase rather than rural to urban migration (Jedwab et al. 2017). 
Housing and the residential capital stock. African cities are short of capital of all sorts, not least in the residential capital stock. Across the continent more than $60 \%$ of the urban population lives in slums, generally single-story shacks, some crowded in town centres, some sprawling on the fringes of the city. In countries such as South Sudan and the Central African Republic, the slum proportion exceeds $90 \%$ (UN-Habitat 2016). A key element of the housing stock - formal, private sector, low-income housing - is largely absent from large cities (Collier, Venables 2015). There are multiple reasons for this; land rights are often unclear and contested, deterring the construction of long-lasting structures; land markets are imperfect, so land is not held by those who value it most; inappropriately high building regulations which cannot be met are simply ignored; financing is difficult as capital and mortgage markets are weak or absent. These features all compound the fact that, urbanising at low income levels, only a low standard of housing is affordable. They mean not only that housing conditions are squalid, but also that land - the ultimate scarce factor in cities - is inefficiently used.

Jobs and the productive capital stock. Just as much of the housing stock is informal, so too is much employment. Estimates of the proportion of the urban labour force with informal sector jobs (i.e., working outside a registered or incorporated enterprise) range up to $80 \%$. A feature of the African situation has been described as 'urbanisation without industrialisation' (Gollin et al. 2016). This refers to the fact that manufacturing production in African cities is much lower than in cities in other regions at a similar stage of development. The share of employment in manufacturing in large Asian cities is typically 25-30\%, while in African cities it is in the range $5-15 \%$. Most of this is in 'non-tradable' sectors producing for the local market. Internationally tradable manufacturing sectors are largely absent, a point we will return to later in the paper.

Infrastructure and the private sector. There are many estimates of the African infrastructure deficit. Annual spending needs have been estimated at around $\$ 90$ billion, amounting to $15 \%$ of African GDP, while actual spending is running at less than 2/3rds of this (Foster, Briceño-Garmendia 2010). The largest elements of this are power, water and sanitation, and connectivity. In each case the urban component is large, totalling perhaps $10 \%$ of GDP per annum sustained over many decades.

Collectively these financing needs - for residential, business, and infrastructure capital, not to mention human capital - typically peak as urban population growth peaks. Africa is not yet at this point, but financing needs might easily amount to as much as $40 \%$ of GDP per annum. East Asian countries have achieved these rates of investment financed by domestic saving. Domestic saving in Africa, typically running at around $15 \%$ of GDP, is unlikely to do so.

Urban governance. Government has an essential role to play in the urban environment. The urban downsides of congestion and contagion mean that provision of infrastructure and public goods and services is particularly important. Effective and appropriate regulation is needed for land, building, and public health. And the formation of a city requires a coordination process that cannot fully be resolved by the market. Uncertainty about the future development of the city - for example, about what areas will become future employment centres - will deter private investment. In order to reduce this uncertainty, expectations of future city development need to be coordinated around common knowledge of where development is likely to take place. This can be done through the provision of credible city plans or, if plans are incredible, through commitments of infrastructure and other public investments.

African cities are severely constrained in their ability to play these roles. Financially, most African cities are dependent on central transfers for more than $80 \%$ of their operating revenues, and local government revenues have been estimated to account for less than $1 \%$ of GDP (Foster, Briceño-Garmendia 2010). City administrations in most major African cities are controlled by national opposition parties, reinforcing 
long-standing central government beliefs that cities are threats rather than assets. To be effective, the authorising environment of city government needs to have broad functional, spatial, and temporal ranges. Often, they have none of these things, with functional responsibilities fragmented across central government line ministries, spatial fragmentation as cities have grown faster than administrative boundaries have been adjusted, and short run political imperatives dominating longer run decision making.

\section{The research agenda}

The city is, from the economic perspective, a general equilibrium system. Millions of different economic agents - households, firms and the public sector - take decisions coordinated largely, but not entirely, by the market mechanism. All parts of the system are inter-dependent meaning that the city, and policy within the city, have to be viewed in the context of the entire system and not just element by element. The benchmark model is that of a monocentric city with workers commuting to the centre to work and residential areas spread around the centre, with density, building height, and rent declining with distance from the centre ${ }^{1}$. This model is useful, but it requires modification in at least three ways if it is to be usefully applied to low income and fast-growing cities.

First, a broad set of market failures and frictions have to be added. These include the issues in the land, housing, and construction markets that were sketched above, and which impede building on land and the efficient allocation of land between alternative uses. They extend to the regulation of firms (for example, obstacles and charges to formalising a productive enterprise) and in the labour market.

Second, the standard model and virtually all the developed country urban literature is static, failing to model the growth process within cities ${ }^{2}$. We have already seen that financing costs will be largest during the most rapid period of urban growth when investment in structures and equipment is at its peak. Incorporating dynamics adds further difficult issues, particularly since buildings (in the formal sector at least) are long-lived and their construction incurs sunk costs. The current state of the city is therefore determined by past actions, so mistaken or delayed decisions have persistent effects, a point we will explore later. It also means that expectations about the future development of the city - and hence the future behaviour of other investors - matter for each individual deciding on an investment.

Third, a useful analysis must incorporate complementarities between different parts of the city system. Many urban interactions create positive feedbacks and hence cumulative causation processes, leading to either 'virtuous' or 'vicious' circles of development. This can occur through many channels. Agglomeration economies are the most direct. The productivity advantages created by scale, density, and consequent intense economic interaction are well-researched for developed, and now also some developing, countries (Glaeser, Xiong 2017). These arise because of positive externalities, either technological (e.g. knowledge spillovers) or pecuniary (i.e. through interaction in imperfect markets). They are generated between different firms (forward and backward linkages in the language of old development economics, e.g. Myrdal 1957), between firms and workers, and between firms and consumers. We know that their effect is substantial with a doubling city of city size raising productivity somewhere in the range of $4 \%-5 \%$.

This productivity gain is one of the reasons why cities exist, and it has a further implication that is particularly important in a fast-growing city. Agglomeration economies mean that is difficult to start activities in new places. This is the first-mover problem; if a firm were to move out of an established centre to a new place it would forego the productivity advantage of agglomeration. In a situation of dynamic change, it follows that movement to new places will be delayed, unless they can be coordinated as collective movement by a large number of firms and households, something that is very hard to achieve. If movement to new places is delayed then the city system will tend to exhibit excess primacy; the largest city will continue growing as it is privately (although not

\footnotetext{
${ }^{1}$ The model Alonso-Mills-Muth model: see Duranton, Puga (2015) for a modern statement.

${ }^{2}$ But see Desmet, Henderson (2015) for a review of growth of city systems as a whole.
} 
socially) unattractive to set up in secondary cities. Within an existing city, it may be difficult for new sub-centres to form, and difficult to attract new sectors of productive activity, this accounting in part for the high levels of informal unemployment that are observed.

Agglomeration economies are not the only mechanism that creates positive feedbacks. Another is the fiscal system. Functional cities require infrastructure, but funding this requires a tax base which is present only if the city is functional. In a dynamic setting where the capital is required at an early stage of development this requires borrowing on the strength of the expected future tax base of the city - something that African cities are likely to find hard to do.

These are just some of the issues that need to be in the research agenda. Analytical thinking on these topics needs to be to be accompanied by empirical work to build an evidence base on city performance and on the effects of policy ${ }^{3}$. The following two sections of the paper turns to a discussion of two of the pieces of analytical work that have been done in the course of the LSE/ Oxford/ World Bank project, looking first at a model of Africa's difficulty in establishing tradable manufacturing sectors, and then at land-use inefficiencies in a growing city $^{4}$.

\section{Breaking into tradables ${ }^{5}$}

A summary way to think about the general equilibrium of a city is as the balance between two forces. One is urban productivity, saying that larger cities generate higher productivity. The other is urban costs per worker, increasing in city size and consisting of commuting and congestion costs, and also land rent paid by workers in the city ${ }^{6}$. Equilibrium city size is where workers' productivity minus urban costs is equal to the productivity of workers outside the city. At this point there is no incentive for workers to migrate either to or from the city.

The standard diagram illustrating this is Figure 2a, where the horizontal axis is city size (the number of workers) and the vertical is labour productivity, equal to wages. The labour demand curve is the amount firms are willing to pay for workers, so is equal to productivity; it is drawn upward sloping because of agglomeration economies. The labour supply curve is what workers need to be paid to take a job in the city. The wage outside the city is $w_{0}$, and workers incur a package of urban costs, increasing in city size as illustrated. The equilibrium is at point $E$ and - in the simplest case - urban land rents are the area below the dashed line and above the labour supply curve.

This simple case rests on many assumptions, one of which we now relax. In reality the city will contain many different productive activities, in some of which productivity is increasing in employment or city size, while in others it is decreasing. Critically, it is value productivity that matters, and this is equal to physical productivity per worker times the price of output. For goods that are internationally tradable the price faced by any one city is constant. However, for 'non-tradables', i.e. goods that are sold only in the local or national market, the price will decline with the volume sold. Thus, we expect such sectors to exhibit overall diminishing returns to scale, as price effects dominate any physical increasing returns that may be present. The productivity schedule in the figure will therefore contain both a diminishing returns segment, and a segment with increasing returns to scale.

This case is illustrated on Figure 2b. The labour supply curve is as before, but labour demand now contains two sections. The downward one is labour demand from non-tradables production, downward sloping because falling output price outweighs any physical productivity gains from expanding output. The upward sloping section is

\footnotetext{
${ }^{3}$ Empirical work on the effects of place-based policy is notoriously difficult for three reasons. The context specificity of particular projects and places, and hence the difficulty of generalising. The identification of causal effect. And, given the possibility of displacement of economic activity, the difficulty of finding a meaningful set of control locations.

${ }^{4}$ See Lall et al. (2017) for a review of other parts of this project.

${ }^{5}$ This section is based on Venables (2017).

${ }^{6}$ Rent is a cost to workers but, since it is paid to landlords, is not a real resource cost as are commuting and congestion.
} 


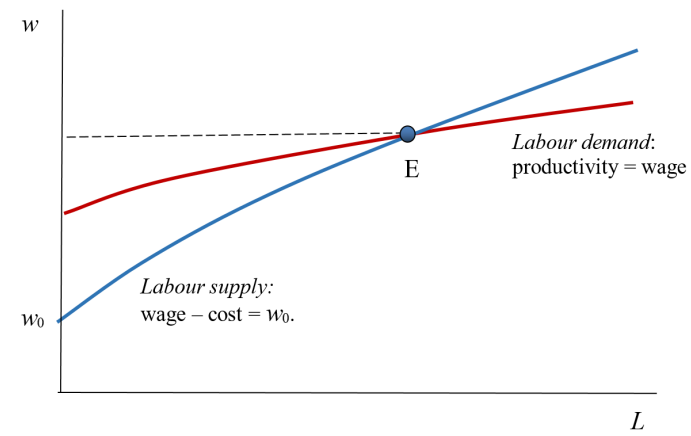

(a) The monocentric city

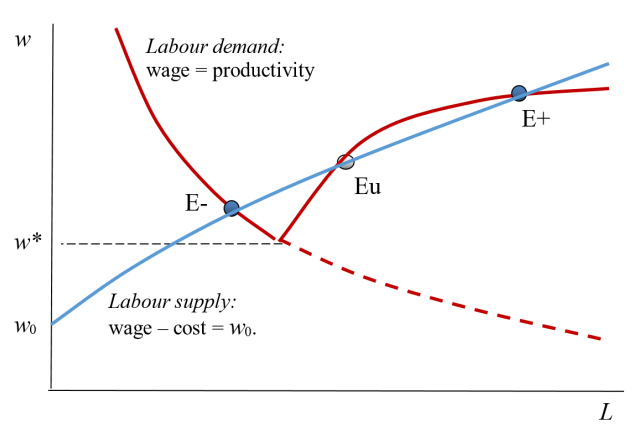

(b) the non-tradables trap

Figure 2: Equilibrium city size

employment in tradable activities, where the price is fixed on world markets and there are agglomeration economies. Details of the construction of the figure are given in Venables (2017) and here we simply draw out its implications. As illustrated, there are three intersections of the productivity schedule with urban costs. The two with solid circles, labelled $E$ - and $E+$ are stable, while that with the hollow circle, $E u$ is unstable (since if $L$ is slightly greater than this then urban productivity is greater than costs, so the city will expand away from this point until it reaches $E+$ ).

Equilibrium $E+$ has production of both tradable and non-tradable goods. The city is large, with high productivity, high nominal wage, but high urban costs, land prices, and rent. As well as creating many jobs, the city yields a large economic surplus as rents, the transfer to landowners, are high. In contrast, at point E- the city has only non-tradables, supplying the city itself and its local hinterland. This point is an equilibrium because if any one (small) firm were to establish tradable production its productivity would be $w *$, i.e. productivity in the absence of agglomeration economics from other tradable sector firms in the city. This is less than the going wage at $E-$, so the entrant would make a loss. Entry is profitable only if productivity in tradables exceeds the going wage at $E-$ and this, in our simple story, requires coordinated entry by a mass of producers in the tradable goods sector.

We learn several things from this simple example. First, although two cities might have very similar or identical fundamentals, an urban dichotomy can emerge. One city booms, with tradable production and employment at $E+$. The other is stuck in a low-level equilibrium at $E-$. Second, the low-level trap is more of a risk if demand for non-tradables is high, this shifting the downward sloping section of the productivity curve to the right. This in turn is likely if the city or its hinterland is spending a lot from income received from other sources, possibly natural resource rents or foreign development assistance. This is an example of the 'Dutch disease' whereby foreign exchange from natural resource rents crowds out other foreign exchange earning activities.

What about policy to get out of this low-level trap? Efficient land-use and provision of infrastructure and public services will shift the cost curve downwards. This lowers the nominal (but not the real) wage in the city, moving intersection point $E$ - downwards and to the right. However, costs have to drop low enough for this point to cease to be an equilibrium, occurring when the wage drops below that which triggers tradable production, $w *$.

One final point comes from this analysis. In a fully specified model which included housing construction, the two equilibria would have quite different housing stocks and urban density. At $E+$ land rents are high so land is used intensively, e.g., by building tall; this is not the case at $E-$, and this makes the low-level equilibrium trap more severe. Essentially, at $E$ - the city is optimised for small-scale local production, while at $E+$ it is optimised for the scale associated with both non-tradable and internationally competitive tradable production. A city in which construction is optimised for $E$ - is going to look even less attractive for potential entrants in the tradables sector. This point emphasises the depth of the coordination failure and the role of expectations. It is 
not just whether firms in tradable goods production expect the tradable sector to grow to a high productivity level. It is whether or not builders and developers build in the expectation of the city growing to this scale. If they do not then their expectations can be self-fulfilling, as the city they construct is low density and thereby offers poor connectivity so is unable to attract these sectors.

\section{$5 \quad$ Building the city ${ }^{7}$}

The second paper that we discuss focuses on the dynamics of city growth and the long-run implications of inefficient land-use. It contains two parts, the first setting out a full dynamic model of a growing city and the second calibrating the model to Nairobi and calculating the efficiency cost of patches of land near the city remaining in slum use, as exemplified by Kibera, Nairobi and Africa's largest slum.

In order to focus on land-use and the way in which the city is built, we assume in this paper that there is an exogenous process of urban productivity growth that is attracting population to the city and causing the price of housing at each point in the city to grow at a constant exponential rate. How is land used and what gets built where and when as this process continues?

Land can have three types of use. One is that it is outside the city, earning a constant rent in agricultural use. The second is that is a slum, occupied by informal sector buildings. These buildings have several key characteristics. They are cheap to construct, but cannot be built tall (typically being made of mud or sheet steel). High density per unit land can be achieved, but only by crowding, this reducing floor space and the well-being of residents. And the building material is malleable (like lego or meccano) so buildings can be readily reshaped and reconstructed. It follows from this that there are no sunk costs and hence future expectations are unimportant in construction decisions; when circumstances change, the building gets changed.

The third type of land-use is formal sector building. This is more expensive and can be built tall. Thus, the margin for increasing density is height, not crowding. The cost of achieving density is therefore not loss of amenity, but increasing unit construction cost. Furthermore, these structures are not malleable; once built they cannot be reshaped, although they can (and will) be demolished and rebuilt from scratch. This means that expectations of future prices and rents are crucial to the way they are constructed; if the city is expected to grow fast, with rapidly increasing rents, formal sector buildings will be constructed taller in order to deliver greater density and capitalise on expected future rents.

As the city develops land-use goes through phases, as illustrated on Figure 3a. This figure has distance from the city centre (CBD) and time on the axes on the horizontal plane, and building volume on the vertical. To interpret the figure, take a given distance from the CBD (e.g., a distance of 10) and trace the development of this point through time (moving up and right across the figure). Initially land at this distance from the CBD is rural, i.e., outside the city with building height and volume of zero. It then becomes informal settlement, which initially is not very dense, although density increases as the city grows and the lego blocks are reconfigured to deliver more density. At some date land is formalised, and this brings a step up in density. Once built, formal structures cannot be changed so building volume remains constant for a period of time $\Delta \tau$. Rents are increasing, and the volume constructed is based on perfect expectations about this future growth in rents, and hence about the date of redevelopment. This is the next step upwards, occurring at the date at which it is efficient (and profit maximising) to demolish the first generation formal structure and redevelop with a taller structure, giving more volume per unit land. These cycles of redevelopment repeat through time as the city continues to grow.

The figure can also be read by slicing in the opposite direction, i.e., looking at a cross-section of the city at a particular date. The centre is built dense, (it has been through several waves of redevelopment), while further out is less dense formal, then

\footnotetext{
${ }^{7}$ This section draws on Henderson et al. (2016).
} 


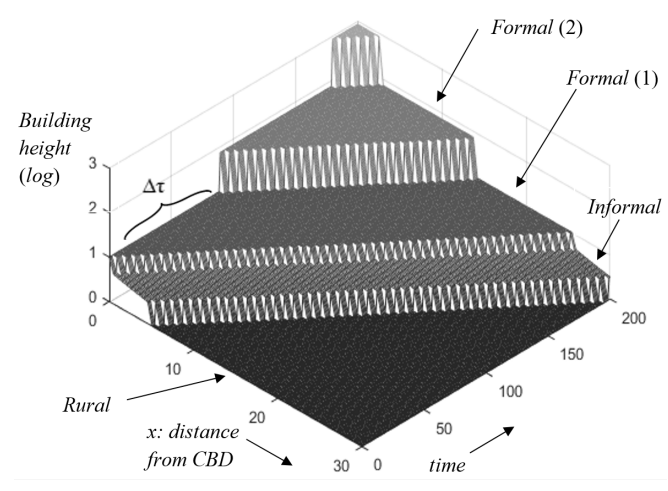

(a) Urban development with perfect foresight

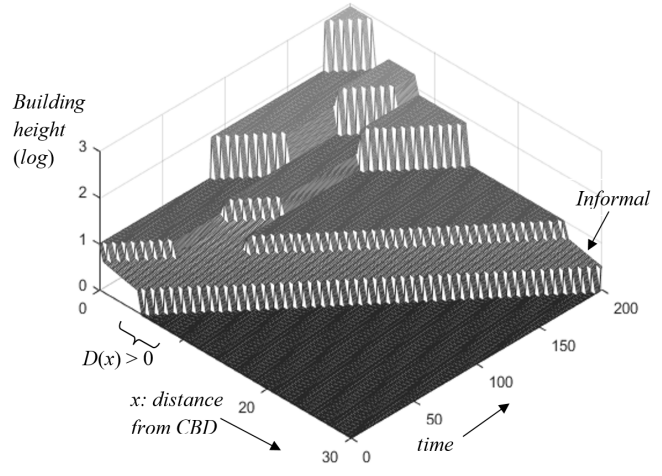

(b) Formalisation costs

Figure 3: Phases of land-use in city development

informal, then rural. Notice that young cities are relatively flat, while more mature cities exhibit much larger volume and density gradients.

This gives the dynamics of city growth in the absence of any imperfections. In this perfect environment formal sector developers have perfect foresight (i.e., self-fulfilling expectations) about the growth of the city. Making expectations more pessimistic than this has the effect of delaying first development and shortening intervals between redevelopment; developers 'under-build' as they under-estimate price and rental growth.

The paper focuses on a different imperfection, namely the presence of obstacles to formalisation, the conversion of land from slum or informal use to formal. There are many such obstacles, typically created by unclear land rights, the difficulty of moving slum residents and, in cases such as Kibera, the power and political connections of 'slum-lords' who are earning rents on the settlement. Figure $3 \mathrm{~b}$ recomputes Figure 3a but with a range of land in which such obstacles are present. As expected, formalisation is delayed. This also has the consequence that when formalisation occurs it is denser (recall that land prices and rents are rising steadily through time), and this echoes through the timing of subsequent redevelopments. If obstacles to redevelopment vary across different places, then the city becomes a 'hodge-podge', with neighbouring pieces of land developed to quite different densities, and the possibility that slums persist in central areas for long periods of time. This gives the familiar image of developing country cities, with slums adjacent to high rise buildings. Central area slums are much denser and more crowded than those on the edge, and have higher land rents.

The second part of the paper calibrates this model to Nairobi. The calibration is based on five distinct types of data. Aerial photography for two points in time, from which the footprint of every building in the city is traced: lidar data (available only for one time period), giving the height of structures: the asking price of vacant land at precisely known locations, scraped from the web: survey data on rentals and aspects of building quality in both the formal and informal sectors: and finally, there are also maps giving the location of areas classified, by previous on-the-ground studies, as slums.

The data reveals very high rates of demolition and redevelopment in the city, these running at around $30 \%$ per decade, compared to less than $10 \%$ in a typical US city. The data validates elements of the model, for example density decreasing steadily with distance from the centre, this taking the form of decreasing height with constant ground cover in the formal sector, while in slums it is decreasing ground cover or crowding, at constant height.

The data also allow calibration of the model, recovering all the key parameters used in the theory. With the model calibrated, we can conduct counterfactual experiments, the main one being to calculate the real income loss of land remaining in informal (slum) use beyond the date at which efficiency suggests it should have been formalised. We find that, in a slum area relatively close to the city centre, such as Kibera, the cost of delayed formalisation is high. The present value real income loss from never formalising, relative for formalising today, amounts to around $\$ 17,000$ per household, even if full 
compensation were paid to slum-lords, in a context where average household rent is around $\$ 700$ per year. Of course, this is only one side of the equation. Redeveloping a slum incurs dislocation costs and the disruption of communities. Nevertheless, the calculation provides an indication of the potential gains from ensuring that timely redevelopment takes place.

\section{Achieving productivity, managing costs}

The urban equilibrium balances urban productivity against urban costs. There are multiple reasons why the market mechanism does not - and cannot - do this in a perfect 'first-best efficient' way. The policy challenge is both to manage and contain urban costs, and to create and coordinate the environment that enables the private sector to achieve productivity. In the urban environment far more than in other contexts, this requires smart and well-motivated public policy. There are numerous aspects to this, and we conclude with a few of the main ones.

Urban costs are brought down by using land efficiently. Labour and capital are in elastic supply to the city, and it is land that is the scarce factor. Securing efficient land-use requires that markets work well - the rental market, the land market, and markets for complementary activities such as mortgages, building materials, and for skilled construction labour and firms. While effective markets are needed, achieving this is not simply a matter of deregulation. The institutional and legal systems need to support clear and enforceable property rights. Building regulations are essential to control potential externalities such as fire risk and to fill informational gaps; the foundations of a house cannot be inspected every time it is traded, so need to be guaranteed by regulation. Provision of decent low-income housing in cities is always problematic and generally requires public investment in the housing stock.

Provision of public services and infrastructure also brings down urban costs. Human well-being is raised by the provision of clean water, sanitation, and public amenities and services, essential to counter the negative externalities of close human contact. The direct benefit of providing these services to households and workers translates into a lower supply price of effective labour to firms, thereby bringing down employment costs and improving competitiveness.

Achieving high productivity requires that firms have access to required inputs, to markets for their output, and to the scale and density of economic interaction that supports agglomeration economies. This can be summarised in the word 'connectivity', and has two distinct elements. One is density which, as we saw in sections 4 and 5 , requires expectations that encourage building formal structures in timely manner. The other is transport infrastructure to mitigate the acute congestion problems of many African cities.

A key point about each of preceding three paragraphs is the need to see the city as a whole. Improving liveability for workers reduces costs for firms. Clarifying land markets leads to better building quality, and hence also to higher density that facilitates agglomeration. The placement of infrastructure, firms, and housing developments are crucial in securing connectivity. Most investment decisions in the city, as elsewhere, are coordinated by markets but we have seen the interdependence of private investment decisions and the role of expectations in shaping such lumpy and long-lasting decisions. If investors do not know which part of a city is most likely to develop as a sub-centre then they will hold back, not investing at all. A coordinating agent - the city government - needs a way of credibly signalling where the new sub-centre will be. This could be through city plans, although often these have no credibility, so signals need to take the concrete form of investment in infrastructure and other structures. The plans drawn up by architects and city planners too often fail to recognise the challenge of attracting jobs; it is easy to plan a future city, but the challenge is to ensure that there is a path to populate it, with firms as well as with people.

Of course, city governments face numerous constraints in playing these roles. Political constraints mean that city governments do not have the breadth of authority to act effectively, or the time horizon to make the long-term investments that are needed. The financial constraint is generally acute with little revenue raised from local taxation and 
dependence on grants from a not always willing central government. Recognising the fact that there is an urban surplus, and that much of it accrues to land owners is crucial. Taxing urban land is equitable, is ethical (land appreciation is due to its location, not the effort of whoever happens to own it) and economically efficient. It is a fiscal resource that is too often under used. And there is a knowledge constraint. Little research has been done on Africa's urban transformation (compare it with the amount of research on rural activities), little of the stock of what we know has been disseminated to policy-makers, and still less has been communicated to the citizens who will shape the future of these cities.

\section{References}

Collier P, Venables AJ (2015) Housing and urbanization in Africa: Unleashing a formal market process. In: Glaeser E, Joshi-Ghani A (eds), The Urban Imperative; Towards Competitive Cities. Oxford University Press, Oxford. CrossRef.

Desmet K, Henderson JV (2015) The geography of development within country. In: Duranton G, Henderson JV, Strange W (eds), Handbook of Regional and Urban Economics, Vol. 5. North-Holland, Amsterdam. CrossRef.

Duranton G, Puga D (2015) Urban land use. In: Duranton G, Henderson JV, Strange W (eds), Handbook of Regional and Urban Economics, Vol. 5. Elsevier, 467-560. CrossRef.

Foster V, Briceño-Garmendia C (2010) Africa's Infrastructure; A Time for Transformation. World Bank, Washington, DC

Glaeser E, Xiong W (2017) Urban productivity in the developing world. Oxford Review of Economic Policy 33: 373-404. CrossRef.

Gollin D, Jedwab R, Vollrath D (2016) Urbanisation with and without industrialisation. Journal of Economic Growth 21: 35-70. CrossRef.

Henderson JV, Regan T, Venables AJ (2016) Building the city: Urban transition and institutional frictions. DP 11211, Centre for Economic Policy Research. Updated version at https://tonyvenables.weebly.com/uploads/1/1/5/4/115449811/buildingcity.pdf

Jedwab R, Christiaensen L, Gindelske M (2017) Demography, urbanisation and development; rural push, urban pull and ... urban push? Journal of Urban Economics 98: 6-16. CrossRef.

Lall S, Henderson JV, Venables AJ (2017) Africa's Cities; Opening doors to the World. World Bank, Washington DC. CrossRef.

Myrdal G (1957) Economic Theory and Underdeveloped Regions. University Paperbacks, Methuen, London

UN-Habitat (2016) Slum almanac 2015-2016. UN-Habitat, Nairobi, https://unhabitat.org/slum-almanac-2015-2016/

Venables AJ (2017) Breaking into tradables: Urban form and urban function in a developing city. Journal of Urban Economics 98: 88-97. CrossRef.

cc) (7) (8) (c) 2018 by the authors. Licensee: REGION - The Journal of ERSA, European Regional Science Association, Louvain-la-Neuve, Belgium. This article is distributed under the terms and conditions of the Creative Commons Attribution, Non-Commercial (CC BY NC) license (http://creativecommons.org/licenses/by-nc/4.0/). 